\title{
Molecular Characterization and Detection of Mutations Associated with Resistance to Succinate Dehydrogenase-Inhibiting Fungicides in Alternaria solani
}

\author{
I. Mallik, S. Arabiat, J. S. Pasche, M. D. Bolton, J. S. Patel, and N. C. Gudmestad
}

First, second, third, and sixth authors: Department of Plant Pathology, North Dakota State University, Fargo 58108; fourth author: United States Department of Agriculture-Agricultural Research Service, Northern Crop Science Laboratory, Fargo, ND 58102; and fifth author: Tropical Research and Education Center, University of Florida, Homestead 33033.

Accepted for publication 19 July 2013

\begin{abstract}
Mallik, I., Arabiat, S., Pasche, J. S., Bolton, M. D., Patel, J. S., and Gudmestad, N. C. 2014. Molecular characterization and detection of mutations associated with resistance to succinate dehydrogenase-inhibiting fungicides in Alternaria solani. Phytopathology 104:40-49.

Early blight, caused by Alternaria solani, is an economically important foliar disease of potato in several production areas of the United States. Few potato cultivars possess resistance to early blight; therefore, the application of fungicides is the primary means of achieving disease control. Previous work in our laboratory reported resistance to the succinate dehydrogenase-inhibiting (SDHI) fungicide boscalid in this plant pathogen with a concomitant loss of disease control. Two phenotypes were detected, one in which A. solani isolates were moderately resistant to boscalid, the other in which isolates were highly resistant to the fungicide. Resistance in other fungal plant pathogens to SDHI fungicides is known to occur due to amino acid exchanges in the soluble subunit succinate dehydrogenase B (SdhB), C (SdhC), and D (SdhD) proteins. In this study, the $A s S d h B, A s S d h C$, and $A s S d h D$ genes were analyzed and compared in sensitive $\left(50 \%\right.$ effective concentration $\left.\left[\mathrm{EC}_{50}\right]<5 \mu \mathrm{g} \mathrm{ml}^{-1}\right)$, moderately resistant $\left(\mathrm{EC}_{50}=5.1\right.$ to $\left.20 \mu \mathrm{g} \mathrm{ml}^{-1}\right)$, highly resistant $\left(\mathrm{EC}_{50}=20.1\right.$ to $\left.100 \mu \mathrm{g} \mathrm{ml}^{-1}\right)$, and very highly resistant $\left(\mathrm{EC}_{50}>100 \mu \mathrm{g} \mathrm{ml}^{-1}\right) A$. solani isolates. In total, five mutations were detected, two in each of the $A s S d h B$ and $A s S d h D$ genes and one in the $A s S d h C$ gene. The sequencing of $A s S d h B$ elucidated point mutations cytosine (C) to thymine (T) at nucleotide 990 and adenine (A) to guanine (G) at nucleotide 991, leading to an exchange from histidine to tyrosine (H278Y) or arginine (H278R), re-

spectively, at codon 278. The H278R exchange was detected in 4 of 10 A. solani isolates moderately resistant to boscalid, exhibiting $\mathrm{EC}_{50}$ values of 6 to $8 \mu \mathrm{g} \mathrm{ml}^{-1}$. Further genetic analysis also confirmed this mutation in isolates with high and very high $\mathrm{EC}_{50}$ values for boscalid of 28 to $500 \mu \mathrm{g}$ $\mathrm{ml}^{-1}$. Subsequent sequencing of $A s S d h C$ and $A s S d h D$ genes confirmed the presence of additional mutations from $\mathrm{A}$ to $\mathrm{G}$ at nucleotide position 490 in $A s S d h C$ and at nucleotide position 398 in the $A s S d h D$, conferring H134R and H133R exchanges in AsSdhC and AsSdhD, respectively. The H134R exchange in AsSdhC was observed in A. solani isolates with sensitive, moderate, highly resistant, and very highly resistant boscalid phenotypes, and the AsSdhD H133R exchange was observed in isolates with both moderate and very high $\mathrm{EC}_{50}$ value boscalid phenotypes. Detection and differentiation of point mutations in $A s S d h B$ resulting in $\mathrm{H} 278 \mathrm{R}$ and H278Y exchanges in the $A s S d h B$ subunit were facilitated by the development of a mismatch amplification mutation assay. Detection of these two mutations in boscalid-resistant isolates, in addition to mutations in $A s S d h C$ and $A s S d h D$ resulting in an H134R and H133R exchange, respectively, was achieved by the development of a multiplex polymerase chain reaction to detect and differentiate the sensitive and resistant isolates based on the single-nucleotide polymorphisms present in all three genes. A single A. solani isolate with resistance to boscalid did not contain any of the above-mentioned exchanges but did contain a substitution of aspartate to glutamic acid at amino acid position 123 (D123E) in the AsSdhD subunit. Among A. solani isolates possessing resistance to boscalid, point mutations in $A s S d h B$ were more frequently detected than mutations in genes coding for any other subunit.
\end{abstract}

Early blight in potato (Solanum tuberosum L.) is caused by the fungal plant pathogen Alternaria solani Sorauer. A. solani causes a distinctive concentric ring pattern on older leaves (16) and, if uncontrolled, can cause significant yield reductions (28). Most commercially acceptable potato cultivars are susceptible to $A$. solani; therefore, the primary means to control the disease is the frequent application of foliar fungicides during the growing season.

The quinone outside-inhibiting (QoI) fungicide azoxystrobin was introduced in 1999 and was used extensively in potato production to manage early blight. The fungicide provided excellent control initially; however, reduced disease control was observed in A. solani by 2001 (31). It is well documented that a mutation in the cytochrome $\mathrm{b}(c y t b)$ gene causing an amino acid substitution of glycine with alanine at position 143 (G143A) conveys full

Corresponding author: N. C. Gudmestad; E-mail address: Neil.Gudmestad@ndsu.edu

http://dx.doi.org/10.1094/PHYTO-02-13-0041-R

(c) 2014 The American Phytopathological Society resistance to QoI fungicides in many other host-pathogen systems, resulting in complete loss of disease control $(11,18,20$ $22,34)$. However, a substitution of phenylalanine with leucine at position 129 (F129L) in cytb in A. solani isolates from commercial potato fields resulted in an $\approx 12$ - to 15 -fold reduction in sensitivity to azoxystrobin (30).

The fungicide boscalid (Endura; BASF Corporation, Agricultural Products, Research Triangle Park, NC) was registered for use on potato in 2005 and became the primary fungicide to control early blight under high disease pressure after the development to resistance in A. solani to azoxystrobin (29). Boscalid is a succinate dehydrogenase-inhibiting (SDHI) fungicide targeting mitochondrial complex II at either succinate ubiquinone reductase or succinate dehydrogenase $(\mathrm{Sdh})$ in the respiratory chain in various pathogens $(3,23)$. The $\mathrm{Sdh}$ complex in fungi comprises four subunits: a flavoprotein (SdhA), an iron sulfur protein consisting of three iron-sulfur clusters $(\mathrm{SdhB})$, and two membraneanchored proteins (SdhC and SdhD). SDHI and QoI fungicides have a similar biochemical mode of action by restricting the mitochondrial respiration at complex II and III, respectively $(30,37)$. 
Initially, boscalid effectively controlled many fungal pathogens, including early blight of potato (29). However, frequent use of SDHI fungicides soon led to the development of resistance to boscalid in various host-pathogen systems such as A. alternata of pistachio (2-6), Botrytis cinerea in several crops $(8,24,27,42)$, Corynespora cassiicola of cucumber $(19,26)$, Didymella bryoniae of cucurbits (7), Monilinia fructicola of peach (1), Podosphaera xanthii of cucumber $(19,26)$, and, finally, A. solani of potato $(14,17,41)$.

Detailed research into the molecular mechanisms involved in boscalid resistance revealed mutations in the SDH complex associated with this resistance. These mutations are primarily present in $S d h B, S d h C$, or $S d h D$ genes $(3,5,6)$. In A. alternata, two mutations in $A a S d h B$ convey either a moderate or high level of resistance to boscalid (5). Point mutations convert a highly conserved histidine residue to either tyrosine (type I) or arginine (type II) at codon position 277 (5). Similarly in D. bryoniae, boscalid resistance is due to amino acid exchanges in the DbSdhB protein, where histidine is substituted by either tyrosine or arginine at codon position 277 (7). A similar situation exists in B. cinerea, in which histidine is substituted at position 272 in the $\mathrm{BcSdhB}$ protein and in C. cassiicola at position 278 (26,42). Two other mutations in A. alternata in the $A a S d h C$ and $A a S d h D$ gene sequences (type III resistance) were shown to convey some level of resistance (6). A mutation in either $C c S d h C$ or $C c S d h D$ also has been implicated in conveying a moderate level of resistance to boscalid in C. cassiicola (26). Recent in vitro assays evaluating sensitivity to SDHI fungicides in our laboratory demonstrated that nearly $80 \%$ of $A$. solani isolates from Colorado, North Dakota, Minnesota, Nebraska, Texas, and Idaho collected in 2010 and 2011 exhibited moderate to very high levels of resistance to boscalid (17). Resistance levels detected in in vitro assays resulted in either a partial or total loss of early blight disease control under greenhouse conditions (17). The objective of this study was to characterize and elucidate the exact molecular mechanisms of boscalid resistance in $A$. solani and to develop molecular diagnostic methods to screen a larger $A$. solani population for boscalid resistance.

\section{MATERIALS AND METHODS}

A. solani isolate collection. Initially, nine A. solani isolates (1178-W1, 1181-13, 1174-5, 1184-15, 1178-E1, 1179-10, 1181-2, $1188-13$, and 1182-13) collected in 2011 with a varying range of $50 \%$ effective concentration $\left(\mathrm{EC}_{50}\right)$ values to the three SDHI fungicides boscalid, penthiopyrad, and fluopyram were chosen arbitrarily for molecular characterization (17). Isolates were revived from long term cryogenic storage in a clarified V8 medium (CV-8) (Campbell's V8 juice, $100 \mathrm{ml} ; \mathrm{CaCO}_{3}, 1.5 \mathrm{~g}$; agar, $15 \mathrm{~g}$; and distilled water, $900 \mathrm{ml}$ ) (31). Isolates were grown for 3 to 4 days at ambient temperature $\left(22 \pm 2{ }^{\circ} \mathrm{C}\right)$. Later, an additional 58 A. solani isolates collected in 2011 (29 isolates) and 2012 (29 isolates) were revived similarly and used for further molecular studies. These isolates were collected primarily from Colorado, Idaho, Minnesota, Nebraska, North Dakota, and Texas.

The in vitro sensitivity of each $A$. solani isolate to SDHI fungicides was determined previously (17) based on conidial germination in the presence of varying concentrations of technical- grade boscalid (B), penthiopyrad (P), and fluopyram $(\mathrm{F})$. The isolates were assigned to a phenotype based on the response $\left(\mathrm{EC}_{50}\right.$ value) of each isolate to the SDHI fungicides. The $\mathrm{EC}_{50}$ value is the concentration of fungicide that reduces mycelial growth or spore germination of the isolate on fungicide-amended media by $50 \%$ compared with growth on nonamended media. The fungicide sensitivity designations assigned to each isolate include sensitive (S) $\left(\mathrm{EC}_{50}<5 \mu \mathrm{g} \mathrm{ml}^{-1}\right)$, moderately resistant $(\mathrm{M})\left(\mathrm{EC}_{50}=5.1\right.$ to $\left.20 \mu \mathrm{g} \mathrm{ml}^{-1}\right)$, highly resistant $(\mathrm{H})\left(\mathrm{EC}_{50}=20.1\right.$ to $\left.100 \mu \mathrm{g} \mathrm{ml}^{-1}\right)$, and very highly resistant $(\mathrm{VH})\left(\mathrm{EC}_{50}>100 \mu \mathrm{g} \mathrm{ml}^{-1}\right)$ phenotypes. This in vitro sensitivity classification system was used to develop a fungicide sensitivity phenotype for each $A$. solani isolate used in the present study and is very similar to that which has been described previously $(7,17)$. For example, an isolate very highly resistant to boscalid, sensitive to fluopyram, and highly resistant to penthiopyrad would be designated $\mathrm{B}^{\mathrm{VH}} \mathrm{F}^{\mathrm{S}} \mathrm{P}^{\mathrm{H}}$.

DNA extraction. Total DNA was extracted from all isolates using a modified cetyltrimethylammonium bromide (CTAB) method (38). Briefly, mycelia and spores were scraped from a 7-day-old culture of $A$. solani into an autoclaved mortar and ground to fine powder with liquid nitrogen. The powder $(100 \mathrm{mg})$ was transferred immediately into a tube of lysing matrix A (MP Biomedicals LLC, OH) consisting of $750 \mu \mathrm{l}$ of Carlson lysis buffer (100 mM Tris $\mathrm{HCl}$ [pH 9.5], 2\% CTAB, $1.4 \mathrm{M} \mathrm{NaCl}, 1 \%$ PEG 8000, and $20 \mathrm{mM}$ EDTA) supplemented with $2 \% \beta$-mercaptoethanol. The tube was placed in a FastPrep instrument (MP Biomedicals) and subjected to agitation at a speed of $6.00 \mathrm{~m} \mathrm{~s}^{-1}$ for $40 \mathrm{~s}$ to facilitate the homogenization of the mycelia and spore mixture. The homogenized sample was incubated in the tube at $75^{\circ} \mathrm{C}$ for $40 \mathrm{~min}$ with inversions at an interval of $10 \mathrm{~min}$ followed by a centrifugation at a speed of $13,500 \times g$ for $10 \mathrm{~min}$. The supernatant was removed and placed into a new tube. Nucleic acids were extracted in the aqueous phase by adding an equal volume of phenol/chloroform/isoamyl alcohol, 25:24:1 (vol/vol) (Sigma-Aldrich, St. Louis, MO). Finally, genomic DNA was precipitated with an equal volume of isopropanol which was washed with $95 \%$ ethanol. The genomic DNA was reconstituted in glass-distilled RNAase-DNAase-free water (Teknova Inc., Hollister, CA) at a final concentration of $10 \mathrm{ng} \mu^{-1}$, after which RNAse $(0.2 \mu \mathrm{g})$ (Qiagen Inc., Valencia, CA) was added.

$A s S d h B, A s S d h C$, and $A s S d h D$ gene sequencing and analysis. The published gene sequences of the A. alternata $A a S d h B$, $A a S d h C$, and $A a S d h D$ genes (National Center for Biotechnology Information [NCBI] accession numbers EU 178851.1, FJ437067.1, and FJ437068.1 respectively) were used as reference sequences to design primers to amplify the respective genes in A. solani (Table 1). The polymerase chain reaction (PCR) was performed using the GoTaq DNA polymerase kit (Promega Corp., Madison, WI) in a $25-\mu \mathrm{l}$ volume consisting of $20 \mathrm{ng}$ of DNA, $1.5 \mathrm{mM} \mathrm{MgCl}$, $0.2 \mathrm{mM}$ dNTP, $5 \mu \mathrm{M}$ each primer, and $1 \mathrm{U}$ of GoTaq polymerase. The PCR was performed in a Peltier thermal cycler, DNA Engine (Bio-Rad, Hercules, CA), with an initial step of $95^{\circ} \mathrm{C}$ for 2 min followed by 30 cycles of denaturation at $95^{\circ} \mathrm{C}$ for $30 \mathrm{~s}$, annealing at $60^{\circ} \mathrm{C}$ for $30 \mathrm{~s}$ and extension at $72^{\circ} \mathrm{C}$ for $1 \mathrm{~min}$. A final extension at $72^{\circ} \mathrm{C}$ for $7 \mathrm{~min}$ concluded the program. The PCR program for amplifying $A s S d h C$ (SdhC-F1 and SdhC-R2) (Table 1) and AsSdhD (SdhD-F1 and SdhD-R2) (Table 1) was as described above, except the final extension cycle was decreased to

TABLE 1. Primers used for sequencing Alternaria solani succinate dehydrogenase (AsSdh) genes

\begin{tabular}{llc}
\hline Primer name & \multicolumn{1}{c}{ Sequence } & Amplicon size (bp) \\
\hline SdhB-F & 5' ATGGCCTCCATACGCGCTTT 3' & 1,082 \\
SdhB-R & 5' CTAGGTGAAGGCCATGCTCTT 3' & \\
SdhC-F1 & 5' ATGGCTTCTCAGCGGGTATTTCAGC 3' & 570 \\
SdhC-R2 & 5' TCCATCCAGTGCGGATAACC 3' \\
SdhD-F1 & 5' ATGGCCTCCGTCATGCGT 3' & 607 \\
SdhD-R2 & 5' CCTCGGTGATACCAACATCGTTTGTC 3' \\
\hline
\end{tabular}


$45 \mathrm{~s}$. The amplified products were separated by gel electrophoresis in $1.2 \%$ agarose (Sigma-Aldrich). The respective bands were excised and cleaned using a Gel extraction kit (Qiagen Inc.), cloned into the pGEM-T Easy vector (Promega Corp.), and sequenced (GeneScript USA Inc., Piscataway, NJ).

The sequences of the three $A s S d h$ genes from all 67 sensitive, moderate, highly resistant, and very highly resistant $A$. solani isolates were analyzed and compared among themselves for homology using Bioedit software (version 7.0.5.3; www.mbio. ncsu.edu/BioEdit/bioedit.html) and to other related fungi using BLAST-based algorithms (http://blast.ncbi.nlm.nih.gov/Blast.cgi). Both BLASTn and BLASTx were performed to detect and annotate the nucleotide and protein sequences. Aligning nucleotide and protein sequences from all $A$. solani isolates using Bioedit revealed single-nucleotide polymorphisms (SNPs) in the respective $A s S d h$ genes associated with resistance.

Molecular detection of SDHI-resistant isolates. The primers for differentiating the mutations in the $A s S d h B$ gene were manually designed based on the rationale of mismatch amplification analysis (MAMA) (Table 2) (12). For specific amplification of the $\mathrm{H} 278 \mathrm{R}$ allele, the reverse primer (MAMABM-R) was designed to have a mismatch at nucleotide position 992 (third nucleotide in from the $3^{\prime}$ end of the primer) of $A s S d h B$, while the ultimate and penultimate nucleotide positions of the primer were specific to mutations encoding the H278R exchange. Likewise, the reverse primer MAMABR-R was designed to have a mismatch at nucleotide position 992 but the penultimate and ultimate nucleotides were specific to mutations encoding the H278Y exchange. The primer sequences developed in this study were verified using Primer-Blast software from NCBI, (http://www.ncbi.nlm.nih.gov/ tools/primer-blast) for any cross-reactivity from other closely related fungi to eliminate false-positive reactions. The MAMAPCR was performed using the GoTaq polymerase kit as described above. The PCR was performed in a Peltier thermal cycler, DNA Engine (Bio-Rad), with an initial preheat step at $95^{\circ} \mathrm{C}$ for $2 \mathrm{~min}$ followed by 30 cycles of denaturation at $95^{\circ} \mathrm{C}$ for $30 \mathrm{~s}$, annealing at $60^{\circ} \mathrm{C}$ for $30 \mathrm{~s}$, and extension at $72^{\circ} \mathrm{C}$ for $1 \mathrm{~min}$. A final extension at $72^{\circ} \mathrm{C}$ for 7 min concluded the program.

Based on SNPs in AsSdhC and AsSdhD associated with resistance to boscalid, multiplex PCR primers were designed using the software Primer-Blast from NCBI (Table 2). The multiplex PCR also consisted of a total volume of $25 \mu \mathrm{l}$, with $20 \mathrm{ng}$ of DNA, $2 \mathrm{mM} \mathrm{MgCl} 2,0.2 \mathrm{mM}$ dNTP, $5 \mu \mathrm{M}$ SdhBSen-F, $5 \mu \mathrm{M}$ SdhBSen-R, $3 \mu \mathrm{M}$ SdhC-F, $3 \mu \mathrm{M}$ SdhC-R1, $5 \mu \mathrm{M}$ SdhD-F, $5 \mu \mathrm{M}$ SdhD-R1, and $1 \mathrm{U}$ of Go Taq polymerase (Promega Corp.). The amplification program was identical to the one used for the MAMAPCR, except that an annealing temperature at $58^{\circ} \mathrm{C}$ was used.

\section{RESULTS}

$A s S d h B, A s S d h C$, and $A s S d h D$ gene sequencing. A full gene sequence of 1,082 bp was obtained for the $A$. solani $A s S d h B$ gene. The gene contained three putative introns and an open reading frame (ORF) encoding a predicted protein of 308 amino acids. Top BLASTn revealed a $93 \%$ identity to $A$. alternata (EU178851.1), 91\% to Pyrenophora tritici-repentis (XM001933224.1), 85\% to C. cassiicola (AB548738.1), and 78\% to Mycosphaerella graminicola (JF916687.1) SdhB genes. Two mutations were found in the $A s S d h B$ gene of $A$. solani isolates with resistance to SDHI fungicides compared with isolates sensitive to the fungicides (Fig. 1A). A mutation from cytosine (C) to thymine (T) at nucleotide position 990 conferred a predicted amino acid exchange from histidine $(\mathrm{H})$ to tyrosine $(\mathrm{Y})$ at AsSdhB amino acid position $278(\mathrm{H} 278 \mathrm{Y})$. A second mutation from adenine (A) to guanine $(\mathrm{G})$ at nucleotide position 991 conferred a predicted amino acid exchange from $\mathrm{H}$ to arginine (R) at AsSdhB amino acid position 278 (H278R). The AsSdhB sequences identified in this study were deposited in GenBank under accession numbers KC517310 to KC517312. The H287R exchange was detected in A. solani isolates with moderately, highly, or very highly resistant boscalid and penthiopyrad phenotypes while the H278R was detected in all phenotypes except in those isolates highly and very highly resistant to penthiopyrad (Table 3).

To identify other mutations that may be involved in SDHI resistance, the $A s S d h C$ and $A s S d h D$ gene were also sequenced. Cloning and subsequent sequencing of $A$. solani As $S d h C$ resulted in $570 \mathrm{bp}$ of partial gene sequence with one putative intron and an ORF encoding a deduced 160-amino-acid protein (accession number KC517313). BLASTn analysis of the derived AsSdhC sequence indicated $92 \%$ similarity to A. alternata AaSdhC (FJ437067.1). A single point mutation from $A$ to $G$ was found in the $A s S d h C$ gene of boscalid-resistant isolates at nucleotide position 490, resulting in a predicted exchange of $\mathrm{H}$ (codon CAC in sensitive isolates) to $\mathrm{R}$ at amino acid position 134 (H134R; codon CGC; accession number KC517314) (Fig. 1B). The H134R exchange generally conveys a moderate to very high resistance to boscalid and high to very high levels of resistance to penthiopyrad (Table 3). However, an individual $A$. solani isolate with the H134R exchange was sensitive to boscalid (1174-9) and, in one instance, to penthiopyrad (1179-13).

The full $A s S d h D$ gene sequence was 607 bp long, with a putative intron and an ORF encoding a predicted 185-amino-acid protein (accession number KC517315). AsSdhD was $90 \%$ similar to A. alternata AaSdhD gene (FJ437068.1). Two mutations were found in the $A s S d h D$ gene. In some isolates with moderate to very high boscalid resistance, a point mutation from $A$ to $G$ at nucleotide position 398 resulted in an exchange from $\mathrm{H}$ (codon CAC in sensitive isolates) to $\mathrm{R}$ at amino acid position 133 (H133R; codon CGC; accession number KC517316) (Fig. 1C). The H133R exchange was detected in isolates displaying moderately and very highly resistant phenotypes to boscalid and moderately and highly resistant phenotypes to penthiopyrad (Table 3). A single A. solani isolate, 1185-7, did not amplify with either of the multiplex and MAMA primers. Sequencing $A s S d h D$ from this isolate revealed a predicted aspartate (D, codon GAC) to glutamic

TABLE 2. Primers used for molecular detection of succinate dehydrogenase-inhibiting (SDHI) fungicide resistant Alternaria solani isolates

\begin{tabular}{|c|c|c|c|c|}
\hline Primer name & Target gene & Sequence & $\mathrm{PCR}^{\mathrm{a}}$ & Amplicon size (bp) \\
\hline SdhBSen-F & $A s S d h B$ & 5' GTCCAAGGAAGACCGCAAGA 3' & Sdh Multiplex & 235 \\
\hline SdhBSen-R & $A s S d h B$ & 5' TGAGCAGTTGAGAATGGTATG 3' & Sdh Multiplex & \\
\hline SdhC-F & AsSdhC & 5' GTCTGAGGGTACAACCCGTG 3' & Sdh Multiplex & 457 \\
\hline SdhC-R1 & $A s S d h C$ & 5' CCTCAAGCCGTTGAAGCTACG 3' & Sdh Multiplex & \\
\hline SdhD-F & As $S d h D$ & 5' GGATCGCTGAACCCCCTTAC 3' & Sdh Multiplex & 72 \\
\hline SdhD-R1 & $A s S d h D$ & 5' CTCAAAGCCAATGTGCGCGC 3' & Sdh Multiplex & \\
\hline MAMAB1-F & $A s S d h B$ & 5' CCCCGCTGTTCTTCTCCAAT 3' & MAMA PCR & 127 \\
\hline MAMABR-R & $A s S d h B$ & $5^{\prime}$ TGAGCAGTTGAGAATGGTATA 3' & MAMA PCR & \\
\hline MAMABM-R & $A s S d h B$ & $5^{\prime}$ TGAGCAGTTGAGAATGGTACG 3' & MAMA PCR & \\
\hline
\end{tabular}

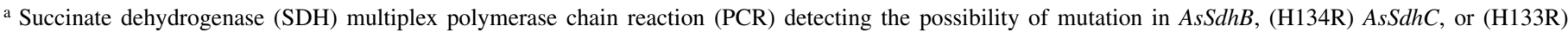
AsSdhD genes. Mismatch amplification analysis (MAMA)-PCR distinguished between H278Y or H278R exchanges in AsSdhB. 
acid (E, codon GAA) substitution in AsSdhD at amino acid position 123 causing the D123E exchange, similar to one reported in A. alternata (6). The D123E exchange conveys very high resistance to boscalid and high resistance to penthiopyrad but comprised just $1.5 \%$ in the population of $A$. solani isolates that were analyzed in the present study (Table 3 ).

All boscalid-resistant $A$. solani isolates in this study possessed only a single mutation in one of the $A s S d h B, A s S d h C$, or $A s S d h D$ genes. Of the 67 A. solani isolates that were analyzed with multiplex PCR, $9 \%$ were sensitive, containing no mutations in any of the three genes; $67 \%$ had either H278R or H278Y exchange in AsSdhB; $7.5 \%$ of isolates possessed an H134R exchange in AsSdhC; and $15 \%$ of the isolates displayed an H133R exchange in AsSdhD.

Association of phenotype distribution and genetic analysis. Based on previously calculated $\mathrm{EC}_{50}$ values for the three SDHI fungicides, in vitro phenotypes were assigned to each $A$. solani isolate. A. solani isolates subsequently were grouped into 11 phenotypes that included one sensitive $\left(\mathrm{B}^{\mathrm{S}} \mathrm{F}^{\mathrm{S}} \mathrm{P}^{\mathrm{S}}\right)$ and $10 \mathrm{SDHI}-$ resistant $\left(\mathrm{B}^{\mathrm{S}} \mathrm{F}^{\mathrm{S}} \mathrm{P}^{\mathrm{H}}, \mathrm{B}^{\mathrm{M}} \mathrm{F}^{\mathrm{S}} \mathrm{P}^{\mathrm{S}}, \mathrm{B}^{\mathrm{M}} \mathrm{F}^{\mathrm{S}} \mathrm{P}^{\mathrm{H}}, \mathrm{B}^{\mathrm{M}} \mathrm{F}^{\mathrm{S}} \mathrm{P}^{\mathrm{VH}}, \mathrm{B}^{\mathrm{H}} \mathrm{F}^{\mathrm{S}} \mathrm{P}^{\mathrm{S}}, \mathrm{B}^{\mathrm{H}} \mathrm{F}^{\mathrm{S}} \mathrm{P}^{\mathrm{H}}\right.$, $\mathrm{B}^{\mathrm{VH}} \mathrm{F}^{\mathrm{S}} \mathrm{P}^{\mathrm{S}}, \mathrm{B}^{\mathrm{VH}} \mathrm{F}^{\mathrm{S}} \mathrm{P}^{\mathrm{M}}, \quad \mathrm{B}^{\mathrm{VH}} \mathrm{F}^{\mathrm{S}} \mathrm{P}^{\mathrm{H}}$, and $\mathrm{B}^{\mathrm{VH}} \mathrm{F}^{\mathrm{S}} \mathrm{P}^{\mathrm{VH}}$ ) phenotypes (Table 3).

Molecular detection of $A s S d h$ mutations was accomplished by the combination of multiplex and MAMA-PCR (Fig. 2). Six isolates of $A$. solani with a sensitive phenotype to the three SDHI fungicides $\left(\mathrm{B}^{\mathrm{S}} \mathrm{F}^{\mathrm{S}} \mathrm{P}^{\mathrm{S}}\right)$ were confirmed by sequencing, MAMA, and multiplex PCR to have no mutations in any of the AsSdh genes (Table 3). Among the 67 A. solani isolates evaluated in this study, 10 SDHI-resistant phenotypes were determined to be conferred by five predicted amino acid substitutions in the AsSdhB, AsSdhC, or AsSdhD subunits.

The H278R exchange in AsSdhB was associated with A. solani isolates with moderate, high, and very high levels of resistance to boscalid but sensitive to other SDHI fungicide phenotypes $\left(\mathrm{B}^{\mathrm{M}} \mathrm{F}^{\mathrm{S}} \mathrm{P}^{\mathrm{S}}, \mathrm{B}^{\mathrm{H}} \mathrm{F}^{\mathrm{S}} \mathrm{P}^{\mathrm{S}}\right.$, and $\mathrm{B}^{\mathrm{VH}} \mathrm{F}^{\mathrm{S}} \mathrm{P}^{\mathrm{S}}$ ) (Table 3). Although the H278R exchange generally did not affect sensitivity to penthiopyrad, some isolates collected from Colorado (1184-15) and Nebraska (1188-18 and 1181-3) were found to have a $\mathrm{B}^{\mathrm{VH}} \mathrm{F}^{\mathrm{S}} \mathrm{P}^{\mathrm{M}}$ phenotype (Table 3). The H278Y exchange in AsSdhB was observed in isolates with moderate to very high levels of resistance to boscalid and, on occasion, moderate to very high resistance to penthiopyrad, resulting in $\mathrm{B}^{\mathrm{M}} \mathrm{F}^{\mathrm{S}} \mathrm{P}^{\mathrm{S}}, \mathrm{B}^{\mathrm{H}} \mathrm{F}^{\mathrm{S}} \mathrm{P}^{\mathrm{S}}, \mathrm{B}^{\mathrm{VH}} \mathrm{F}^{\mathrm{S}} \mathrm{P}^{\mathrm{S}}, \mathrm{B}^{\mathrm{VH}} \mathrm{F}^{\mathrm{S}} \mathrm{P}^{\mathrm{M}}, \mathrm{B}^{\mathrm{VH}} \mathrm{F}^{\mathrm{S}} \mathrm{P}^{\mathrm{H}}$, and $\mathrm{B}^{\mathrm{VH}} \mathrm{F}^{\mathrm{S}} \mathrm{P}^{\mathrm{VH}}$ phenotypes.

The H134R exchange in AsSdhC was observed most frequently in A. solani isolates with moderate to high levels of resistance to boscalid and high to very high levels of resistance to penthiopyrad, resulting in $\mathrm{B}^{\mathrm{S}} \mathrm{F}^{\mathrm{S}} \mathrm{P}^{\mathrm{H}}, \mathrm{B}^{\mathrm{M}} \mathrm{F}^{\mathrm{S}} \mathrm{P}^{\mathrm{VH}}, \mathrm{B}^{\mathrm{H}} \mathrm{F}^{\mathrm{S}} \mathrm{P}^{\mathrm{S}}$, and $\mathrm{B}^{\mathrm{H}} \mathrm{F}^{\mathrm{S}} \mathrm{P}^{\mathrm{H}}$ phenotypes. However, a single isolate collected from North Dakota (1239-20) with the H134R exchange was found to have a $\mathrm{B}^{\mathrm{VH}} \mathrm{F}^{\mathrm{S}} \mathrm{P}^{\mathrm{VH}}$ phenotype.

The H133R exchange in AsSdhD was detected in A. solani isolates with multiple phenotypes. Most of these isolates were recovered from Idaho. This exchange was found primarily in isolates having moderate to very high resistance to boscalid and moderate resistance to penthiopyrad, resulting in $\mathrm{B}^{\mathrm{M}} \mathrm{F}^{\mathrm{S}} \mathrm{P}^{\mathrm{S}}$, $\mathrm{B}^{\mathrm{M}} \mathrm{F}^{\mathrm{S}} \mathrm{P}^{\mathrm{H}}, \mathrm{B}^{\mathrm{VH}} \mathrm{F}^{\mathrm{S}} \mathrm{P}^{\mathrm{S}}, \mathrm{B}^{\mathrm{VH}} \mathrm{F}^{\mathrm{S}} \mathrm{P}^{\mathrm{M}}$, and $\mathrm{B}^{\mathrm{VH}} \mathrm{F}^{\mathrm{S}} \mathrm{P}^{\mathrm{H}}$ phenotypes. One of the A. solani isolates evaluated in this study, 1185-7, recovered from Nebraska, was found to have a predicted substitution of an aspartate to glutamic acid at amino acid position 123 (D123E) in the AsSdhD subunit. This particular mutation was associated with very high and high levels of resistance to boscalid and penthiopyrad, respectively, resulting in a $\mathrm{B}^{\mathrm{VH}} \mathrm{F}^{\mathrm{S}} \mathrm{P}^{\mathrm{H}}$ phenotype. This mutation was not detected in any of the other A. solani isolates used in this study.

In summary, isolates of $A$. solani with moderate to very high $\mathrm{EC}_{50}$ values for boscalid (13 to $500 \mu \mathrm{g} \mathrm{ml}^{-1}$ ) and variable responses to penthiopyrad from sensitive to very high $\mathrm{EC}_{50}$ values $\left(0.4\right.$ to $\left.>100 \mu \mathrm{g} \mathrm{ml}^{-1}\right)$ were dominated by the $\mathrm{H} 278 \mathrm{Y}$ exchange in AsSdhB. In contrast, the H134R exchange in AsSdhC was associated most frequently with high $\mathrm{EC}_{50}$ values for penthio-

A

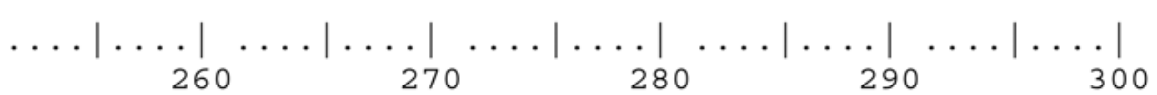
AsSdhB-S.seq RWIADSRDEK KAERQDALNN SMSLYRCHTI LNCSRTCPKG LNPALAIAEI AsSdhB-M.seq RWIADSRDEK KAERQDALNN SMSLYRCRTI LNCSRTCPKG LNPALAIAEI AsSdhB-R.seq RWIADSRDEK KAERQDALNN SMSLYRCYTI LNCSRTCPKG LNPALAIAEI

B

$$
\begin{aligned}
& \ldots|\ldots| \ldots|\ldots| \ldots|\ldots| \ldots|\ldots| \ldots|\ldots| \ldots \mid \\
& \begin{array}{llll}
110 & 120 & 130 & 140
\end{array} \\
& \text { AsSdhC-S.seq WHMETQSMVA TVAAWPAAAK AGLKAFYAFP FFFHSFNGLR HLSWDVGIGF }
\end{aligned}
$$$$
\text { AsSdhC-R.seq WHMETQSMVA TVAAWPAAAK AGLKAFYAFP FFFRSFNGLR HLSWDVGIGF }
$$

C

$$
\begin{aligned}
& \ldots|\ldots| \ldots|\ldots| \ldots|\ldots| \ldots|\ldots| \ldots|\ldots| \ldots \mid \\
& 110 \quad 120 \quad 130 \quad 140 \quad 150 \\
& \text { AsSdhD-S.seq VSAGLIPLTI APFAAGSLNP LTDSILCALL VVHSHIGFES CIIDYFPAKR }
\end{aligned}
$$$$
\text { AsSdhD-R.seq VSAGLIPLTI APFAAGSLNP LTDSILCALL VVRSHIGFES CIIDYFPAKR }
$$

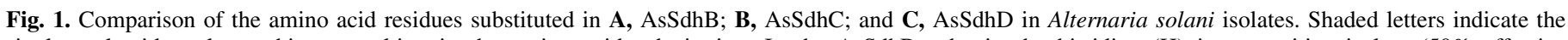

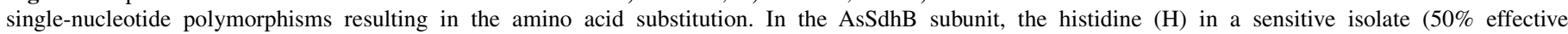

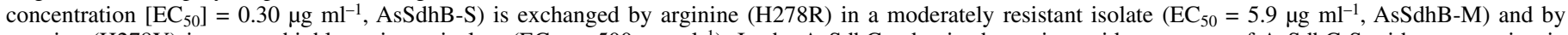

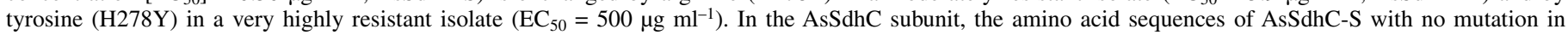

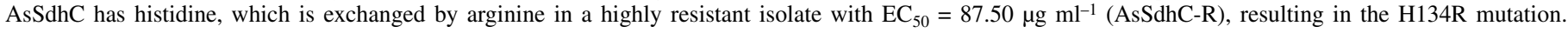

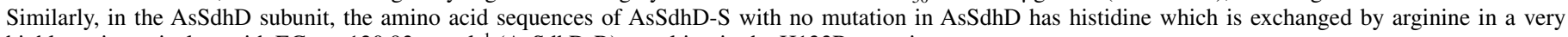
highly resistant isolate with $\mathrm{EC}_{50}=120.93 \mu \mathrm{g} \mathrm{ml}^{-1}$ (AsSdhD-R), resulting in the H133R mutation. 
pyrad (35 to $112 \mu \mathrm{g} \mathrm{ml}^{-1}$ ) and boscalid (49 to $161 \mu \mathrm{g} \mathrm{ml}^{-1}$ ). Although $A$. solani isolates with mutations in the $A s S d h B$ gene were found to be evenly distributed throughout the United States, this was not true of other mutations in other subunits. Approximately $90 \%$ of $A$. solani isolates displaying the H133R exchange in AsSdhD were collected from Idaho, with the remaining $10 \%$ from Nebraska. Similarly, $\approx 80 \%$ of the boscalid-resistant $A$. solani isolates with an $\mathrm{H} 134 \mathrm{R}$ exchange in AsSdhC were collected from North Dakota, with the remaining 20\% from Idaho.

Molecular detection of SDHI-resistant isolates. MAMA primers were developed to distinguish SNPs for two mutations in $A s S d h B$ associated with moderate to very high resistance to boscalid (Table 2; Fig. 2). Amplification with MAMAB1-F and MAMABM-R primers developed for isolates with a mutation resulting in $\mathrm{H} 278 \mathrm{R}$ exchange conveying moderate and high $\mathrm{EC}_{50}$ values to boscalid yielded a 127-bp amplification product and no products in sensitive and some highly resistant isolates (Table 2; Fig. 3A). Similarly, amplification with MAMAB1-F and MAMABR-R primers developed for isolates with a mutation resulting in $\mathrm{H} 278 \mathrm{Y}$ exchange conveying very high $\mathrm{EC}_{50}$ values for boscalid yielded a 127-bp amplification product on agarose gel but none for sensitive and moderately resistant isolates (Table 2; Fig. 3B). However, isolates determined to have mutations in $A s S d h C$ and $A s S d h D$ genes conveying moderate or high boscalid $\mathrm{EC}_{50}$ values produced no bands in either H278R or H278Y MAMA-PCR (data not shown), requiring the development of additional assays for their detection and differentiation.
SNPs in $A s S d h C$ and $A s S d h D$ that conferred the H134R and H133R amino acid exchanges in AsSdhC and AsSdhD subunits, respectively, were the basis of this multiplex PCR assay (Table 2). A 235-bp amplification product along with either a 457-bp product (Fig. 4, lanes 7 and 8) or 72-bp product (Fig. 4, lanes 9 and 10) were amplified if an exchange existed in AsSdhC or AsSdhD, respectively. A single amplification product of $235 \mathrm{bp}$ (Fig. 4, lanes 1 and 2) confirmed that an isolate did not possess any of the mutations in $A \mathrm{~s} S d h B, A \mathrm{~s} S d h C$, and $A s S d h D$ genes resulting in the exchanges described above. Absence of any amplification products (Fig. 4, lanes 3 to 6) indicated that there is a possible exchange in AsSdhB, confirmed by the MAMA-PCR described above.

\section{DISCUSSION}

It has been documented previously that boscalid-resistant A. solani isolates are prevalent in many states such as Colorado, Idaho, Minnesota, Nebraska, North Dakota, and Texas $(14,17,41)$. Based on in vitro spore germination assays and in vivo disease control studies, it also was demonstrated that there are two phenotypes of boscalid resistance and that isolates with resistance to boscalid are not necessarily cross-resistant to other SDHI fungicides such as fluopyram or penthiopyrad (17). This is consistent with other studies that have demonstrated variable patterns of cross resistance among SDHI fungicides in other plant-pathogenic fungi $(3,7,15,19,40)$. For example, in previous studies, isolates of

TABLE 3. In vitro fungicide sensitivity and molecular characterization of Alternaria solani isolates based on succinate dehydrogenase-inhibiting (SDHI) fungicide phenotypes

\begin{tabular}{|c|c|c|c|c|c|c|c|}
\hline \multirow[b]{2}{*}{ Isolate } & \multirow[b]{2}{*}{ Location } & \multicolumn{3}{|c|}{ Fungicide $\mathrm{EC}_{50}$ values $(\mu \mathrm{g} / \mathrm{ml})^{\mathrm{a}}$} & \multirow[b]{2}{*}{ Sequencing ${ }^{\mathrm{b}}$} & \multirow[b]{2}{*}{ Sdh multiplex/MAMA-PCR ${ }^{\mathrm{c}}$} & \multirow[b]{2}{*}{ SDH phenotype ${ }^{\mathrm{d}}$} \\
\hline & & Boscalid & Fluopyram & Penthiopyrad & & & \\
\hline $1252-4$ & Idaho & 0.24 & 0.26 & 0.33 & CAC-Alle & Sensitive & $\mathrm{B}^{\mathrm{S}}-\mathrm{F}^{\mathrm{S}}-\mathrm{P}^{\mathrm{S}}$ \\
\hline 1178-W1 & Idaho & 0.28 & 0.75 & 0.45 & CAC-Alle & Sensitive & \\
\hline $1168-1$ & Idaho & 0.30 & 0.31 & 0.03 & CAC-All ${ }^{\mathrm{e}}$ & Sensitive & \\
\hline $1248-12$ & Idaho & 0.42 & 0.31 & 0.34 & CAC-Alle & Sensitive & \\
\hline $1190-14$ & Minnesota & 0.60 & 1.85 & 1.93 & CAC-Alle & Sensitive & \\
\hline 1181-13 & Nebraska & 0.65 & 0.20 & 0.43 & CAC-Alle & Sensitive & \\
\hline $1174-9$ & Idaho & 4.65 & 2.00 & 47.00 & CGC-SdhC & $\mathrm{H} 134 \mathrm{R}(\mathrm{C})$ & $\mathrm{B}^{\mathrm{S}}-\mathrm{F}^{\mathrm{S}}-\mathrm{P}^{\mathrm{H}}$ \\
\hline $1176-3$ & Idaho & 5.80 & 2.45 & 2.16 & CGC-SdhD & H133R (D) & 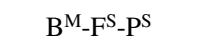 \\
\hline $1172-8$ & Idaho & 7.40 & 2.65 & 2.52 & CGC-SdhD & H133R (D) & \\
\hline 1178-E1 & Idaho & 5.90 & 0.34 & 0.58 & CGC-SdhB & H278R (B) & \\
\hline $1172-6$ & Idaho & 6.00 & 0.37 & 1.64 & CGC-SdhB & H278R (B) & \\
\hline $1224-4$ & Nebraska & 6.05 & 0.29 & 0.37 & CGC-SdhB & H278R (B) & \\
\hline $1229-19$ & Texas & 6.20 & 0.04 & 0.17 & CGC-SdhB & H278R (B) & \\
\hline $1252-8$ & Idaho & 12.96 & 0.27 & 2.26 & TAC-SdhB & H278Y(B) & \\
\hline $1226-12$ & Texas & 17.45 & 0.26 & 2.05 & TAC-SdhB & $\mathrm{H} 278 \mathrm{Y}(\mathrm{B})$ & \\
\hline $1176-5$ & Idaho & 6.25 & 2.15 & 25.46 & CGC-SdhD & H133R (D) & $\mathrm{B}^{\mathrm{M}}-\mathrm{F}^{\mathrm{S}}-\mathrm{P}^{\mathrm{H}}$ \\
\hline $1231-9$ & North Dakota & 6.46 & 3.26 & $>100.00$ & CGC-SdhC & $\mathrm{H} 134 \mathrm{R}(\mathrm{C})$ & $\mathrm{B}^{\mathrm{M}}-\mathrm{F}^{\mathrm{S}}-\mathrm{P}^{\mathrm{VH}}$ \\
\hline $1236-3$ & Minnesota & 27.52 & 0.26 & 0.38 & CGC-SdhB & H278R(B) & $\mathrm{B}^{\mathrm{H}_{-}} \mathrm{F}^{\mathrm{S}}-\mathrm{P}^{\mathrm{S}}$ \\
\hline $1192-10$ & Minnesota & 41.40 & 0.47 & 0.24 & CGC-SdhB & H278R(B) & \\
\hline $1217-6$ & Nebraska & 31.40 & 0.39 & 2.32 & TAC-SdhB & H278Y(B) & \\
\hline $1179-13$ & North Dakota & 87.50 & 1.02 & 4.31 & CGC-SdhC & $\mathrm{H} 134 \mathrm{R}(\mathrm{C})$ & \\
\hline $1179-14$ & North Dakota & 49.00 & 2.25 & 35.51 & CGC-SdhC & $\mathrm{H} 134 \mathrm{R}(\mathrm{C})$ & $\mathrm{B}^{\mathrm{H}}-\mathrm{F}^{\mathrm{S}}-\mathrm{P}^{\mathrm{H}}$ \\
\hline $1217-12$ & Nebraska & 500.00 & 0.23 & 0.57 & CGC-SdhD & H133R (D) & 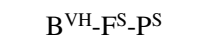 \\
\hline $1254-5$ & Idaho & 500.00 & 2.06 & 1.60 & CGC-SdhD & H133R (D) & \\
\hline $1175-8$ & Idaho & 120.93 & 2.05 & 2.59 & CGC-SdhD & H133R (D) & \\
\hline $1230-1$ & Texas & 120.33 & 0.38 & 1.12 & CGC-SdhB & $\mathrm{H} 278 \mathrm{R}(\mathrm{B})$ & \\
\hline $1198-14$ & Nebraska & 123.35 & 0.44 & 1.74 & CGC-SdhB & H278R(B) & \\
\hline
\end{tabular}

${ }^{\mathrm{a}} \mathrm{EC}_{50}$ value is the concentration of fungicide that reduces mycelial growth or spore germination of the isolate on fungicide-amended media by $50 \%$ compared with growth on nonamended media.

${ }^{\mathrm{b}} \mathrm{SDH}$ sequencing of the respective gene with single nucleotide polymorphism, where $\mathrm{C}=$ cytosine, $\mathrm{A}=$ adenine, $\mathrm{G}=$ guanine, and $\mathrm{T}=$ thymine

${ }^{c}$ SDH multiplex polymerase chain reaction (PCR) detecting the possibility of point mutations in $A s S d h B$, (H134R) AsSdhC, or (H133R) AsSdhD genes and mismatch amplification analysis (MAMA)-PCR to distinguish between H278Y or H278R exchanges in AsSdhB; $\mathrm{H}=$ histidine, $\mathrm{R}=$ arginine, $\mathrm{Y}=$ tyrosine, $\mathrm{D}=$ aspartate, and $\mathrm{E}=$ glutamic acid.

${ }^{\mathrm{d}}$ Phenotype of sensitivity to SDHI fungicides boscalid (B), fluopyram (F), and penthiopyrad $(\mathrm{P}) . \mathrm{S}=$ sensitive $\left(\mathrm{EC}_{50}<5 \mu \mathrm{g} \mathrm{ml} \mathrm{l}^{-1}\right), \mathrm{M}^{-1} \mathrm{moderate}\left(\mathrm{EC}_{50}=5.1\right.$ to $\left.20 \mu \mathrm{g} \mathrm{ml}{ }^{-1}\right), \mathrm{H}=$ highly resistant $\left(\mathrm{EC}_{50}=20.1\right.$ to $\left.100 \mu \mathrm{g} \mathrm{ml}^{-1}\right)$, and $\mathrm{VH}=$ very highly resistant $\left(\mathrm{EC}_{50}>100 \mu \mathrm{g} \mathrm{ml}{ }^{-1}\right)$.

${ }^{\mathrm{e}} \mathrm{CAC}$ codon is not mutated in $A s S d h B$ (at amino acid position 278), $A s S d h C$ (at amino acid position 134), and AsSdhD (at amino acid position 133). 
A. alternata, D. bryoniae, C. cassiicola, and Podosphaera xanthii resistant to boscalid were found to be sensitive to fluopyram $(3,7,19)$. The main objective of this study was to characterize the mutations responsible for boscalid resistance in A. solani and to develop effective molecular detection methods that can be used to screen additional isolates of the pathogen in other potato-production areas of the United States where early blight is problematic. Understanding the mutations that affect sensitivity to SDHI fungicides at a molecular level may enhance our understanding of the fungicide resistance acquired by this fungus and may assist in designing more effective fungicide resistance management strategies to control the disease.

In the current study, several mutations specific to A. solani were identified in the $S d h B, S d h C$, and $S d h D$ genes encoding the iron-sulfur protein and the anchor proteins of the Sdh complex. Five different point mutations in these $A s S d h$ genes leading to amino acid substitutions in the AsSDH subunits were identified. These point mutations resulted in $10 \mathrm{SDHI}$ resistance phenotypes, each with variable effects on the sensitivity to fungicides boscalid, fluopyram, and penthiopyrad. Although point mutations on the $S d h B, S d h C$, and $S d h D$ genes have been associated previously with resistance to boscalid in A. alternata (2-6) and $C$. cassiicola (26), in other plant-pathogenic fungi such as $D$. bryoniae (7) and $B$. cinerea $(39,40,42)$, point mutations in the $S d h B$ gene have been found to be solely responsible for boscalid resistance. In $M$. graminicola, UV mutagenesis has demonstrated that carboxin resistance is primarily due to point mutations in the
$S d h B$ gene but that point mutations in the $S d h C$ and $S d h D$ subunits are possible $(15,33,36)$. Mutations in $S d h C$ and $S d h D$ genes have been determined also to be responsible for boscalid resistance in B. cinerea in Europe (25). Nonetheless, the data reported here demonstrate the complexity that confronted us in understanding SDHI resistance in A. solani.

Point mutations in the gene encoding the soluble hydrophilic subunit AsSdhB were the most common identified among the $A$. solani isolates studied. Sequencing of the $A s S d h B$ gene revealed a point mutation leading to the H278Y or H278R exchanges. The H278R exchange was associated consistently with isolates exhibiting a moderate level of resistance to boscalid and penthiopyrad but sensitive to fluopyram. However, 10 isolates displaying high or very high resistance to boscalid also contained this mutation. The H278Y exchange was associated primarily with isolates with high or very high levels of boscalid resistance. The lack of point mutation in the $A s S d h B$ subunit in several isolates with varying levels of resistance to boscalid led to the investigation of other mutations in the membrane-anchored subunits AsSdhC and AsSdhD. Sequencing of $A s S d h C$ and $A s S d h D$ genes from $A$. solani isolates with varying levels of resistance to SDHI fungicides but no mutation in the $A s S d h B$ gene confirmed the presence of H134R and H133R exchanges in the AsSdhC and AsSdhD subunits, respectively. Although the mutation in the $A s S d h C$ gene was observed most commonly in A. solani isolates with moderate and high boscalid resistance, one isolate (1174-9) was sensitive to boscalid but highly resistant to penthiopyrad. In

TABLE 3. (continued from preceding page)

\begin{tabular}{|c|c|c|c|c|c|c|c|}
\hline \multirow[b]{2}{*}{ Isolate } & \multirow[b]{2}{*}{ Location } & \multicolumn{3}{|c|}{ Fungicide $\mathrm{EC}_{50}$ values $(\mu \mathrm{g} / \mathrm{ml})^{\mathrm{a}}$} & \multirow[b]{2}{*}{ Sequencing ${ }^{b}$} & \multirow[b]{2}{*}{ Sdh multiplex/MAMA-PCR ${ }^{c}$} & \multirow[b]{2}{*}{ SDH phenotype ${ }^{\mathrm{d}}$} \\
\hline & & Boscalid & Fluopyram & Penthiopyrad & & & \\
\hline $1181-15$ & Nebraska & 129.64 & 0.22 & 0.31 & CGC-SdhB & $\mathrm{H} 278 \mathrm{R}(\mathrm{B})$ & $\mathrm{B}^{\mathrm{VH}}-\mathrm{F}^{\mathrm{S}}-\mathrm{P}^{\mathrm{S}}$ \\
\hline $1230-15$ & Texas & 270.11 & 0.46 & 1.81 & CGC-SdhB & H278R(B) & \\
\hline $1220-4$ & Minnesota & 121.16 & 0.27 & 0.41 & TAC-SdhB & H278Y(B) & \\
\hline $1192-2$ & Minnesota & 127.68 & 0.23 & 2.80 & TAC-SdhB & H278Y(B) & \\
\hline $1221-15$ & Minnesota & 129.10 & 0.53 & 1.75 & TAC-SdhB & H278Y(B) & \\
\hline $1174-5$ & Idaho & $>100.00$ & 0.04 & 1.75 & CGC-SdhB & H278R (B) & \\
\hline $1201-5$ & Nebraska & 129.63 & 0.36 & 2.69 & TAC-SdhB & H278Y(B) & \\
\hline $1180-2$ & North Dakota & 130.96 & 0.31 & 4.06 & TAC-SdhB & H278Y(B) & \\
\hline $1181-2$ & Nebraska & 143.67 & 0.30 & 2.34 & TAC-SdhB & H278Y(B) & \\
\hline $1238-17$ & North Dakota & 143.99 & 0.20 & 2.28 & TAC-SdhB & H278Y(B) & \\
\hline $1229-2$ & Texas & 145.01 & 0.42 & 3.04 & TAC-SdhB & $\mathrm{H} 278 \mathrm{Y}(\mathrm{B})$ & \\
\hline $1190-16$ & Minnesota & 151.66 & 0.48 & 1.62 & TAC-SdhB & $\mathrm{H} 278 \mathrm{Y}(\mathrm{B})$ & \\
\hline $1179-8$ & North Dakota & 154.35 & 0.33 & 1.98 & TAC-SdhB & H278Y(B) & \\
\hline $1201-23$ & Nebraska & 251.22 & 0.31 & 2.82 & TAC-SdhB & H278Y(B) & \\
\hline $1179-2$ & North Dakota & 278.92 & 0.24 & 4.77 & TAC-SdhB & H278Y(B) & \\
\hline $1220-22$ & Minnesota & 324.66 & 1.49 & 1.21 & TAC-SdhB & H278Y(B) & \\
\hline $1198-22$ & Nebraska & 500.00 & 0.04 & 4.13 & TAC-SdhB & $\mathrm{H} 278 \mathrm{Y}(\mathrm{B})$ & \\
\hline $1179-3$ & North Dakota & 500.00 & 0.30 & 3.10 & TAC-SdhB & H278Y(B) & \\
\hline $1182-13$ & Nebraska & 500.00 & 0.38 & 1.49 & TAC-SdhB & H278Y(B) & \\
\hline $1254-9$ & Idaho & 143.22 & 1.44 & 16.55 & CGC-SdhD & H133R (D) & $\mathrm{B}^{\mathrm{VH}}-\mathrm{F}^{\mathrm{S}}-\mathrm{P}^{\mathrm{M}}$ \\
\hline $1175-4$ & Idaho & 135.15 & 1.45 & 19.10 & CGC-SdhD & H133R (D) & \\
\hline $1246-15$ & Idaho & 273.92 & 0.38 & 13.96 & CGC-SdhD & H133R (D) & \\
\hline $1188-18$ & Nebraska & 500.00 & 0.37 & 13.42 & CGC-SdhB & $\mathrm{H} 278 \mathrm{R}(\mathrm{B})$ & \\
\hline $1227-16$ & Texas & 112.94 & 0.44 & 5.48 & TAC-SdhB & H278Y(B) & \\
\hline $1236-8$ & Minnesota & 114.96 & 0.25 & 12.67 & TAC-SdhB & H278Y(B) & \\
\hline $1223-4$ & Minnesota & 129.83 & 0.44 & 12.67 & TAC-SdhB & $\mathrm{H} 278 \mathrm{Y}(\mathrm{B})$ & \\
\hline $1250-1$ & Idaho & 138.74 & 1.96 & 16.80 & TAC-SdhB & $\mathrm{H} 278 \mathrm{Y}(\mathrm{B})$ & \\
\hline $1187-11$ & Nebraska & 155.38 & 0.25 & 18.57 & TAC-SdhB & H278Y(B) & \\
\hline $1184-15$ & Colorado & $>100.00$ & 0.01 & 8.09 & CGC-SdhB & H278R (B) & \\
\hline $1181-3$ & Nebraska & $>100.00$ & 0.17 & 17.46 & CGC-SdhB & H278R (B) & \\
\hline $1188-13$ & Nebraska & 267.27 & 0.58 & 7.59 & TAC-SdhB & H278Y(B) & \\
\hline $1222-15$ & Minnesota & 500.00 & 0.39 & 18.12 & TAC-SdhB & $\mathrm{H} 278 \mathrm{Y}(\mathrm{B})$ & \\
\hline $1173-7$ & Idaho & $>100.00$ & 4.00 & 28.87 & CGC-SdhD & H133R (D) & $\mathrm{B}^{\mathrm{VH}}-\mathrm{F}^{\mathrm{S}}-\mathrm{P}^{\mathrm{H}}$ \\
\hline $1185-7$ & Nebraska & $>100.00$ & 1.89 & 30.63 & GAA-SdhD & D123E(D) & \\
\hline $1234-11$ & Minnesota & 113.87 & 0.41 & 62.62 & TAC-SdhB & H278Y(B) & \\
\hline $1179-10$ & North Dakota & 114.43 & 0.30 & 72.32 & TAC-SdhB & H278Y(B) & \\
\hline $1189-19$ & Nebraska & 350.49 & 0.46 & 21.15 & TAC-SdhB & H278Y(B) & \\
\hline $1189-7$ & Nebraska & 500.00 & 0.42 & 22.80 & TAC-SdhB & $\mathrm{H} 278 \mathrm{Y}(\mathrm{B})$ & \\
\hline $1184-20$ & Colorado & 132.07 & 1.46 & $>100.00$ & TAC-SdhB & H278Y(B) & $\mathrm{B}^{\mathrm{VH}}-\mathrm{F}^{\mathrm{S}}-\mathrm{P}^{\mathrm{VH}}$ \\
\hline $1239-20$ & North Dakota & 161.38 & 3.75 & 111.97 & CGC-SdhC & $\mathrm{H} 134 \mathrm{R}(\mathrm{C})$ & \\
\hline
\end{tabular}


comparison, mutations in the $A s S d h D$ gene were observed in isolates with moderate, high, and very high boscalid resistance.

Molecular characterization of SDH gene mutations in other plant-pathogenic fungi have revealed a similar variation in the SDH subunits involved and in the resulting expression of resistance $(3,35,42)$. In $A$. alternata, isolates displaying boscalid fungicide resistance had point mutations in $A a S d h$ genes that likely reduced affinity in binding to the target site, resulting in reduced efficacy (3). In total, five SNPs in the fungal AaSdh genes were characterized in A. alternata. Among isolates with boscalid resistance, $45 \%$ had an $\mathrm{H} 277 \mathrm{Y}$ exchange and 35\% had an $\mathrm{H} 277 \mathrm{R}$ exchange in the AaSdhB subunit (5). Further studies of 22 additional $A$. alternata isolates with no mutations in the $A a S d h B$ gene but with high resistance to boscalid had a point mutation in $A a S d h C$, resulting in an H134R genotype. Subsequent molecular analyses revealed two A. alternata mutants with a genotype of H134R and one mutant with a D123E exchange as a result of point mutation in the $A a S d h D$ gene (6). Not surprisingly, results of the studies reported here on $A$. solani demonstrate that mutations in the $A s S d h B$ gene are also the most frequently detected but that mutations in the $A s S d h C$ and $A s S d h D$ genes can be important in some geographic areas of the United States. In direct contrast,

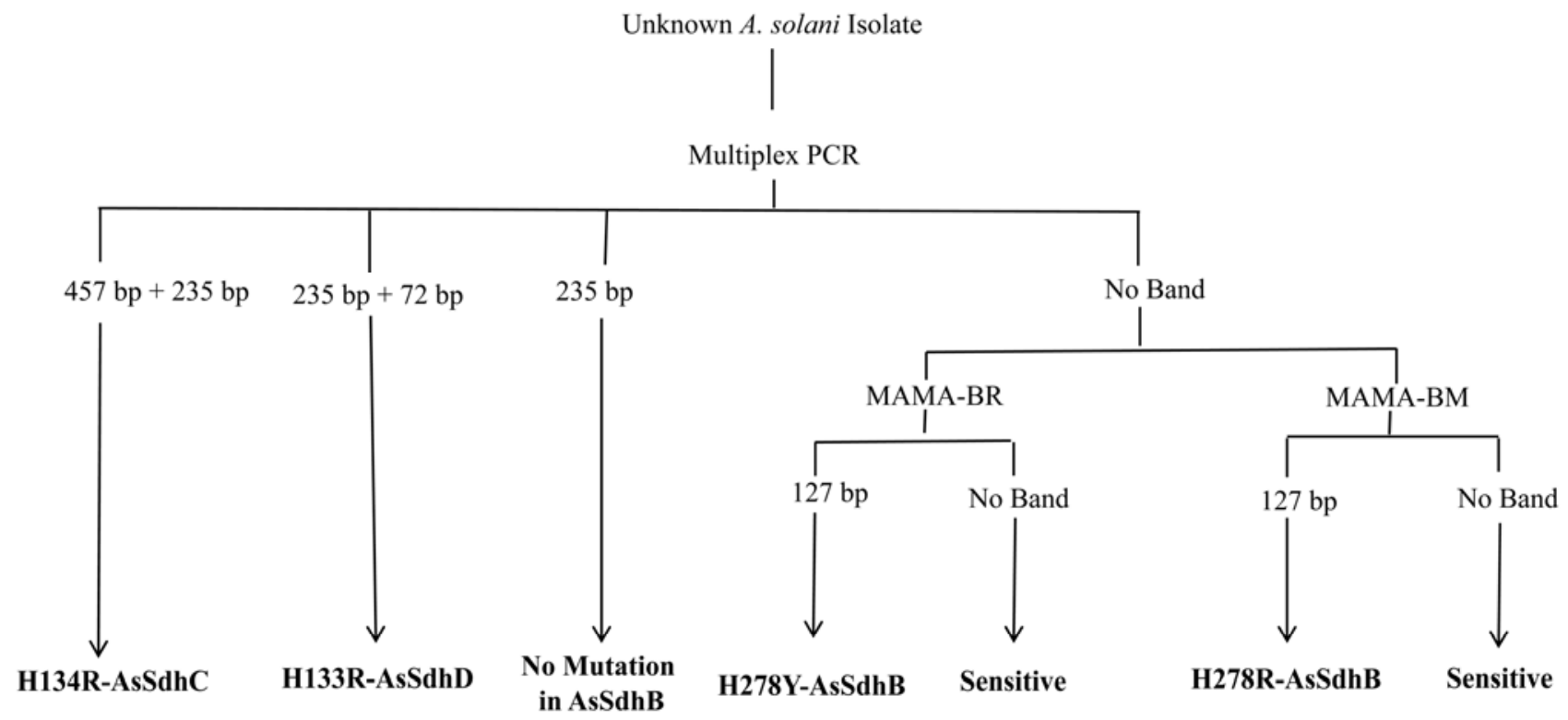

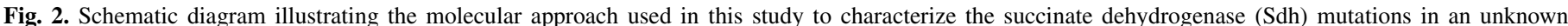

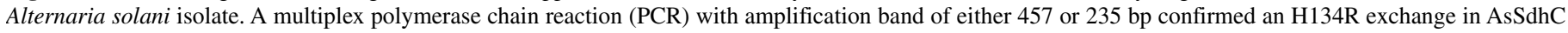

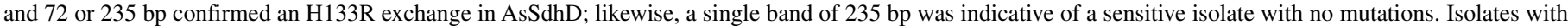

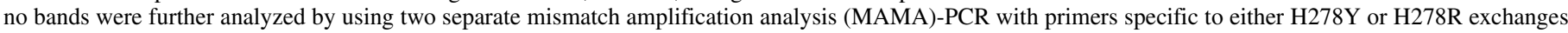

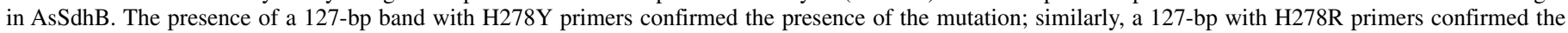
mutation in AsSdhB. If there were no bands in both the MAMA-PCRs, the isolate was sensitive.
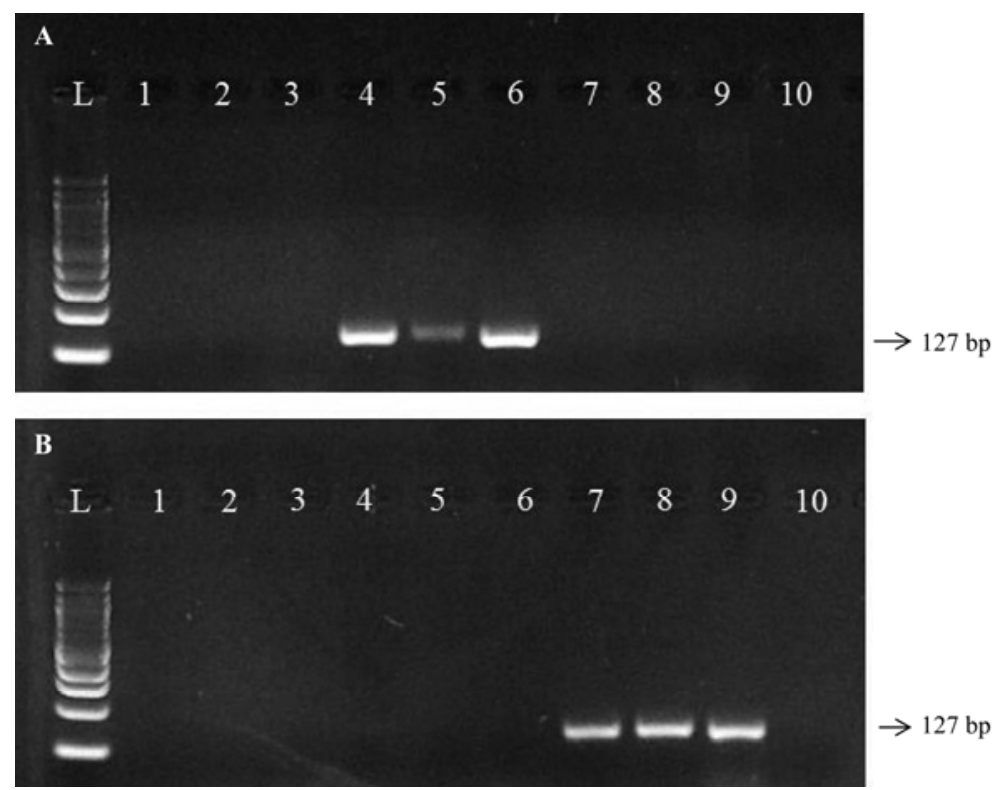

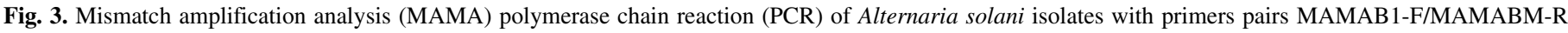

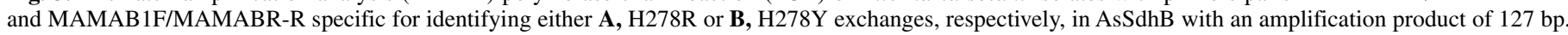

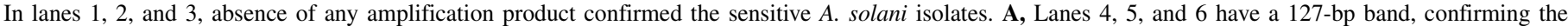

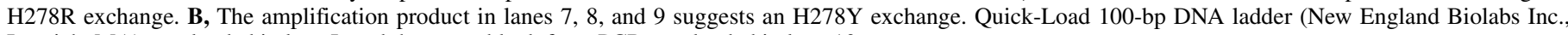
Ipswich, MA) was loaded in lane L and the water blank from PCR was loaded in lane 10. 
genotypic variation in the $D b S d h B$ gene was shown to be responsible for boscalid and penthiopyrad resistance in $D$. bryoniae, with $\mathrm{H} 277 \mathrm{Y}$ and $\mathrm{H} 277 \mathrm{R}$ being the most predominant mutations (7). However, point mutations in the $D b S d h C$ and $D b S d h D$ genes in this plant-pathogenic fungus were not investigated (7).

Perhaps the most intriguing finding of the study reported here was that all of the $A$. solani isolates with fungicide-resistant phenotypes exhibited a single point mutation in one of the three $A s S d h$ genes, presumably leading to a decrease in the affinity to boscalid and reduced sensitivity to the fungicide (17). To date, none of these point mutations appear to affect the efficacy of the SDHI fungicide fluopyram, regardless of the plant-pathogenic fungus $(3,7,17,19,40)$. However, in A. solani, a few isolates have decreased in vitro sensitivity to fluopyram compared with the baseline (i.e., 1231-9, 1173-7, and 1239-20). From the studies reported here, it appears that H134R exchanges in AsSdhC and H133R in AsSdhD convey some decreased sensitivity to this fungicide but, based on previous studies on A. solani (29-31), we would not expect these slight decreases in sensitivity to affect fungicide efficacy. Further studies are required to determine whether this is an anomaly or an indication that point mutations in this SDH subunit could convey some loss of efficacy of fluopyram. Furthermore, it has been determined previously that mutations in the $A a S d h D$ gene in A. alternata occurred at a very low frequency and eventually disappeared $(3,6)$. The disappearance of this mutation within the A. alternata population was attributed to a selective disadvantage under field conditions, perhaps due to increased susceptibility to oxidative stress $(3,6)$. In the current study, a number of AsSdhD mutants with H133R (15\%) exchanges conferring resistance to boscalid were detected, several of which have decreased sensitivity to fluopyram compared with the baseline (17). Further survey work is planned to determine whether other $A$. solani isolates can be detected with decreased sensitivity to fluopyram and whether or not the $A s S d h \mathrm{D}$ mutation carries any fitness penalty, as observed in A. alternata. Although it has been determined that there is no fitness penalty associated with the F129L mutation in A. solani cytb that is associated with QoI resistance (29), we do not know if the presence of multiple fungicide resistance mutations will affect the ability of this plant-pathogenic fungus to compete in the absence of selection pressure. Nearly $100 \%$ of the A. solani isolates with boscalid resistance are also resistant to QoI fungicides by virtue of the F129L mutation in the cytb gene (17), warranting further investigation.

There is also considerable variation in the phenotypic expression of sensitivity to each specific SDHI fungicide among the point mutations detected in the SDH subunits of $A$. solani. For example, the $\mathrm{H} 278 \mathrm{Y}$ exchanges in AsSdhB conveyed high to very high levels of resistance to boscalid whereas isolates with this mutation remained sensitive to fluopyram and, in some cases, a few isolates remained sensitive to penthiopyrad. However, a majority of the isolates with the H278Y exchange also had moderate to high resistance to penthiopyrad in addition to resistance to boscalid. A similar situation existed in A. solani isolates with the H278R exchange in AsSdhB, where most isolates were moderately to highly resistant to boscalid but remained sensitive to fluopyram and penthiopyrad. Inexplicably, there were also a few isolates with the H278R exchange with moderate or high resistance to penthiopyrad. This is in contrast to mutations in the $S d h B$ gene in $A$. alternata and $D$. bryoniae which convey very consistent phenotypic expressions of resistance to boscalid and penthiopyrad $(3,5,7)$. However, in $B$. cinerea, point mutations resulting in $\mathrm{H} 272 \mathrm{R}$ and $\mathrm{H} 272 \mathrm{Y}$ exchanges in $\mathrm{BcSdhB}$ were not associated with any particular resistance phenotype $(40,42)$, very similar to that observed with $A$. solani reported here. It has been suggested that SDH mutations are species specific and that these mutations frequently display differential patterns in levels of the resistance conveyed (35). Furthermore, there also can be significant variation in sensitivity to a specific fungicide across isolates of the same fungal species carrying the identical mutation in the SDH enzyme (35). A good example of this are A. solani isolates with the H134R exchange which was generally found in isolates with moderate to very high levels of resistance to boscalid but was also found in a single boscalid-sensitive isolate (1174-9). In other words, the differential expression of fungicide sensitivity conveyed by $A s S d h$ mutations in $A$. solani is not unique and should not be unexpected. Whether or not the variability in phenotypic expression in $A$. solani resulting from a specific point mutation is due to some uncharacterized mechanism, as has been suggested elsewhere (33), is not known.

The spatial distribution of mutations among the SDH subunits in $A$. solani was of particular interest. Mutations in the $A s S d h B$ gene were not only the most common but were also generally distributed among all states where SDHI resistance has been reported (17). This was not found to be true of the H133R exchange in the AsSdhD subunit or the H134R exchange in the AsSdhC subunit, which were found to predominate in A. solani isolates recovered from Idaho and North Dakota, respectively. Although we have no immediate explanation for this, there is evidence of considerable spatial variability in the SDH subunits conveying resistance in other plant-pathogenic fungi. Several studies exploring the resistance to SDHI fungicides in mutants of $B$. cinerea have suggested a number of genotypic variations that are spatially distributed. For example, field isolates from Ger-

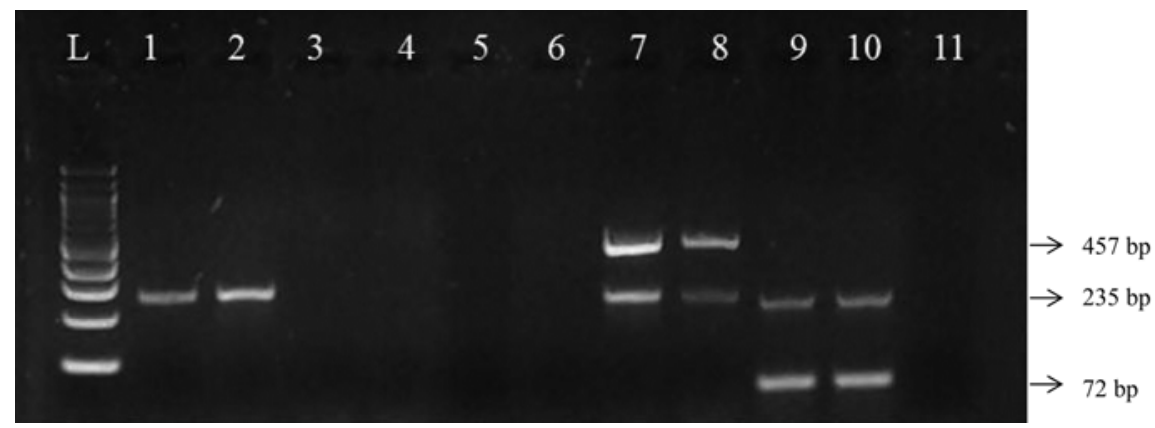

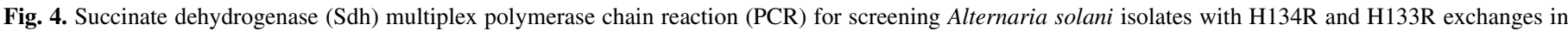

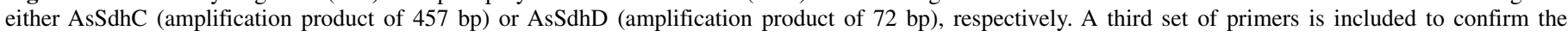

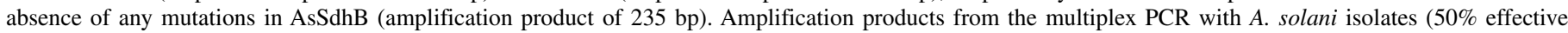

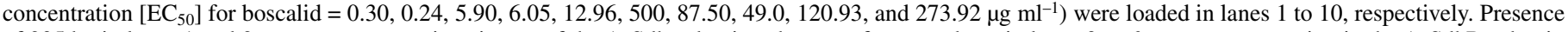

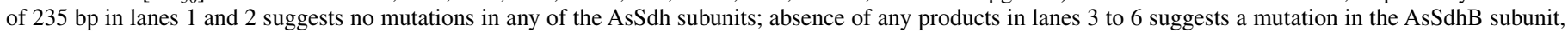

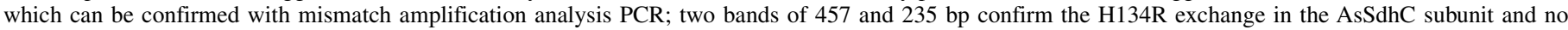

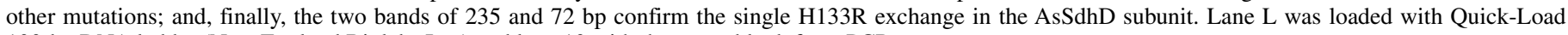
100-bp DNA ladder (New England Biolabs Inc.) and lane 10 with the water blank from PCR. 
many and France displayed mutations in the $S d h B$ gene conferring amino acid substitutions H272Y, H272R, or H272L (25). Although H272L was not encountered in $B$. cinerea in a large number of isolates, when observed, it was responsible for a high level of resistance to SDHI fungicides in specific locations (25). A second set of modifications in the $B c S d h B$ gene involving a substitution of proline to either tyrosine (P225T), leucine (P225L), or phenylalanine $(\mathrm{P} 225 \mathrm{~F})$ were characterized and considered to be specific only to carboxamide-resistant Botrytis isolates (25). Similar alleles were discovered in B. cinerea isolates from Greece (H272L and $\mathrm{P} 225 \mathrm{~F}$ ) highly resistant to boscalid, although occurring in low frequency $(39,40)$. In contrast, $B$. cinerea isolated from apple in the United States contained only two genotypic alleles of $B c S d h B$ resulting from $\mathrm{H} 272 \mathrm{Y}$ or $\mathrm{H} 272 \mathrm{R}$ exchanges (42).

The development of molecular methods to detect the point mutations associated with boscalid and penthiopyrad resistance was an important goal of this research. Less than 200 A. solani isolates were evaluated initially for boscalid resistance in a previous study (17) and, in the studies reported here, $\approx 67$ isolates were characterized at the molecular level. Because there is spatial variability in the presence of boscalid resistance (17) and in the location of specific point mutations as demonstrated in the current study, it will be important to evaluate a much larger population of A. solani from the United States. Previously, several molecular methods involving allele-specific PCR and restriction fragment length polymorphism assays have been developed to identify resistance to specific fungicides rapidly and efficiently $(5,6,9,10$, $13,25,30,32,39)$. Although these detection methods have many positive attributes, a number of the methods developed can be time consuming when used to screen a large fungal population. In this study, there was a single nucleotide difference between $\mathrm{H} 278 \mathrm{R}$ and $\mathrm{H} 278 \mathrm{Y}$ alleles at adjacent positions in $A s S d h B$. Therefore, we felt the technique involving MAMA primers with specific mismatches at the third nucleotide at the $3^{\prime}$ end to permit preferential amplification of one allele relative to another would be useful in the detection and differentiation of these two point mutations in $A s S d h B$. The pair of MAMA-primers developed in this study to screen for boscalid resistance in the $A s S d h B$ gene of A. solani was found to be very effective and efficient, which is critical because mutations in this subunit were the most frequently detected in the population. The frequent lack of sensitivity observed with MAMA technique was not encountered in this study, as indicated by validating the results of MAMA PCR by sequencing. The detection and differentiation of mutations present in the $A s S d h C$ and $A s S d h D$ genes were further facilitated using a multiplex PCR. This was accomplished by designing primers that yielded different sizes of amplification products that were specific for isolates with point mutations in the $A s S d h C$ and $A s S d h D$ genes. This technique rapidly and efficiently detects the mutation site in a single reaction, while identifying $A$. solani isolates sensitive to SDHI fungicides using primer pairs for the wild-type $A s S d h B$ sequence. The presence of two amplification products in the multiplex PCR indicates a single mutation in either $A s S d h C$ or $A s S d h D$ but not in $A s S d h B$. We believe that using a combination of the MAMA and multiplex PCR assays for the detection and differentiation of these mutations can be performed more rapidly and cost effectively than other methods previously described (57,25,39).

Future studies will concentrate on determining the frequency of these mutations in a much more spatially and temporally diverse A. solani population. Such studies will not only reveal the overall distribution of each point mutation but also, perhaps, determine whether other mutations that convey resistance to SDHI fungicides such as fluopyram exist since this fungicide was first registered for use in 2012. There is considerable concern that, with the current status of resistance to boscalid, fluxapyroxad, and penthiopyrad (17), that there will be increased use of fluopyram which will undoubtedly place significant selection pressure on the early blight pathogen. It has been suggested that all SDH mutations convey, in essence, cross resistance to all SDHI fungicides at the population level (35). If this is indeed true, then it is likely just a matter of time before resistance to fluopyram becomes evident given the predominance of boscalid-resistant phenotypes which are believed to "preselect" populations with an increased probability to develop reduced sensitivity or resistance (35). Moreover, further selection pressure on A. solani in response to fluopyram may lead to the appearance of additional point mutations in the population that are, at this point, not known to exist.

\section{ACKNOWLEDGMENTS}

We thank H. F. Avenot for his guidance in aligning A. solani sequences and providing A. alternata isolates as controls for initial polymerase chain amplification reactions, and Bayer CropScience and DuPont for their financial support.

\section{LITERATURE CITED}

1. Amiri, A., Brannen, P. M., and Schnabel, G. 2010. Reduced sensitivity in Monilinia fructicola field isolates from South Carolina and Georgia to respiration inhibitor fungicides. Plant Dis. 94:737-743.

2. Avenot, H. F., and Michailides, T. J. 2007. Resistance to boscalid fungicide in Alternaria alternata isolates from pistachio in California. Plant Dis. 91:1345-1350.

3. Avenot, H. F., and Michailides, T. J. 2010. Progress in understanding molecular mechanisms and evolution of resistance to succinate dehydrogenase inhibiting (SDHI) fungicides in phytopathogenic fungi. Crop Prot. 29:643-651.

4. Avenot, H. F., Morgan, D. P., and Michailides, T. J. 2008. Resistance to pyraclostrobin, boscalid and multiple resistance to Pristine ${ }^{\circledR}$ (pyraclostrobin + boscalid) fungicide in Alternaria alternata causing Alternaria late blight of pistachios in California. Plant Pathol. 57:135-140.

5. Avenot, H. F., Sellam, A., Karaoglanidis, G., and Michailides, T. J. 2008. Characterization of mutations in the iron-sulphur subunit of succinate dehydrogenase correlating with boscalid resistance in Alternaria alternata from California pistachio. Phytopathology 98:736-742.

6. Avenot, H. F., Sellam, A., and Michailides, T. J. 2009. Characterization of mutations in the membrane-anchored subunits of AaSDHC and AaSDHD of succinate dehydrogenase from Alternaria alternata isolates conferring field resistance to the fungicide boscalid. Plant Pathol. 58:1134-1143.

7. Avenot, H. F., Thomas, A., Gitaitis, R. D., Langston, D. B., Jr., and Stevenson, K. 2012. Molecular characterization of boscalid- and penthiopyrad-resistant isolates of Didymella bryoniae and assessment of their sensitivity to fluopyram. Pest Manage. Sci. 68:645-651.

8. Bardas, G. A., Veloukas, T., Koutita, O., and Karaoglanidis, G. S. 2010. Multiple resistance of Botrytis cinerea from kiwifruit to SDHIs, QoIs and fungicides of other chemical groups. Pest Manage. Sci. 66:967-973.

9. Billard, A., Laval, V., Fillinger, S., Leroux, P., Lachaise, H., Beffa, R., and Debieu, D. 2011. The allele-specific probe and primer amplification assay, a new real-time PCR method for fine quantification of single nucleotide polymorphisms in pooled DNA. Appl. Environ. Microbiol. 78:1063-1068.

10. Birla, K., Rivera-Varas, V., Secor, G. A., Khan, M. F. R., and Bolton, M. D. 2012. Characterization of cytochrome $b$ from European field isolates of Cercospora beticola with quinone outside inhibitor resistance. Eur. J. Plant Pathol. 134:475-488.

11. Bolton, M. D., Rivera, V., and Secor, G. 2013. Identification of the G143A mutation associated with QoI resistance in Cercospora beticola field isolates from Michigan, United States. Pest Manage. Sci. 69:35-39.

12. Cha, R. S., Zarbl, H., Keohavong, P., and Thilly, W. G. 1992. Mismatch amplification mutation assay (MAMA): Application to the $\mathrm{cH}-\mathrm{ras}$ gene. Genome Res. 2:14-20.

13. Delgado, J. A., Lynnes, T. C., Meinhardt, S. W., Wise, K. A., Gudmestad, N. C., Bradley, C. A., Markell, S. G., and Goswami, R. S. 2013. Identification of the mutation responsible for resistance to Qol fungicides and its detection in Ascochyta rabiei (telemorph Didymella rabiei). Plant Pathol. 62:688-697.

14. Fairchild, K. L., Miles, L. A., Miles, T. D., and Wharton, P. S. 2012. Detection and characterization of boscalid resistance in Alternaria solani causing early blight on potatoes in Idaho. (Abstr.) Phytopathology 102(suppl.):S4.36.

15. Fraaije, B. A., Bayon, C., Atkins, S., Cools, H. J., Lucas, J. A., and Fraaije, M. W. 2012. Risk assessment studies on succinate dehydrogenase inhibitors, the new weapons in the battle to control Septoria leaf blotch in wheat. Mol. Plant Pathol. 13:263-275. 
16. Franc, G. D., and Christ, B. J. 2001. Early blight. Pages 22-23 in: Compendium of Potato Diseases. W. R. Stevenson, R. Loria, G. D. Franc, and D. P. Weingartner, eds. American Phytopathological Society, St. Paul, MN.

17. Gudmestad, N. C., S. Arabiat, S., Pasche, J. S., and Miller, J. S. 2013. Prevalence and impact of SDHI fungicide resistance in Alternaria solani. Plant Dis. 97:952-960.

18. Ishii, H., Fraaije, B. A., Sugiyama, T., Noguchi, K., Nishimura, K., Takeda, T., Amano, T., and Hollomon, D. W. 2001. Occurrence and molecular characterization of strobilurin resistance in cucumber powdery mildew and downy mildew. Phytopathology 91:1166-1171.

19. Ishii, H., Miyamoto, T., Ushio, S., and Kakishima, M. 2011. Lack of cross-resistance to a novel succinate dehydrogenase inhibitor, fluopyram, in highly boscalid-resistant isolates of Corynespora cassiicola and Podosphaera xanthii. Pest Manage. Sci. 67:474-482.

20. Kim, Y. S., Dixon, E. W., Vincelli, P., and Farman, M. L. 2003. Field resistance to strobilurin (QoI) fungicides in Pyricularia grisea caused by mutations in the mitochondrial cytochrome $b$ gene. Phytopathology 93:891-900.

21. Köller, W. K., Avila-Adame, C., Olaya, G., and Zheng, D. 2001. Resistance to strobilurin fungicides. Pages 215-229 in: Agrochemical Resistance: Extent, Mechanism, and Detection. J. M. Clark and I. Yamaguchi, eds. American Chemical Society, Washington, DC.

22. Köller, W. K., Parker, D. M., Turechek, W. W., Avila-Adame, C., and Cronshaw, K. 2004. A two-phase resistance response of Venturia inequalis populations to the QoI fungicides kresoxim-methyl and trifloxystrobin. Plant Dis. 88:537-544.

23. Kuhn, P. J. 1984. Mode of action of carboximides. Symp. Ser. Br. Mycol. Soc. 9:155-183.

24. Leroch, M., Kretschmer, M., and Hahn, M. 2011. Fungicide resistance phenotypes of Botrytis cinerea isolates from commercial vineyards in South West Germany. J. Phytopathol. 159:63-65.

25. Leroux, P., Gredt, M., Leroch, M., and Walker A.-S. 2010. Exploring mechanisms of resistance to respiratory inhibitors in field strains of Botrytis cinerea, the causal agent of gray mold. Appl. Environ. Microbiol. 76:6615-6630.

26. Miyamoto, T., Ishii, H., Stammler, G., Koch, A., Ogawara, T., Tomita, Y., Fountaine, J.M., Ushio, S., Seko, T., and Kobori, S. 2010. Distribution and molecular characterization of Corynespora cassiicola isolates resistant to boscalid. Plant Pathol. 59:873-881.

27. Myresiotis, C. K., Bardas, G. A., and Karaglanidis, G. S. 2008. Baseline sensitivity of Botrytis cinerea to pyraclostrobin and boscalid and control of anilinopyrimdine- and benzimidazole-resistant strains by these fungicides. Plant Dis. 92:1427-1431.

28. Olanya, O. M., Honeycutt, C. W., Larkin, R. P., Griffin, T. S., He, Z., and Halloran, J. M. 2009. The effect of cropping systems and irrigation management on development of potato early blight. J. Gen. Plant Pathol. 7:267-275.
29. Pasche, J. S., and Gudmestad, N. C. 2008. Prevalence, competitive fitness and impact of the F129L mutation in Alternaria solani in the United States. Crop Prot. 27:427-443.

30. Pasche, J. S., Piche, L. M., and Gudmestad, N. C. 2005. Effect of F129L mutation in Alternaria solani on fungicides affecting mitochondrial respiration. Plant Dis. 89:269-278.

31. Pasche, J. S., Wharam, C. M., and Gudmestad, N. C. 2004. Shift in sensitivity of Alternaria solani to QoI fungicides. Plant Dis. 88:181-187.

32. Patel, J. S., Meinhardt, S. W., Sierotzki, H., Stammler, G., Gudmestad, N. C., and Adhikari, T. B. 2011. A two-step molecular detection method for Pyrenophora tritici-repentis isolates insensitive to QoI fungicides. Plant Dis. 95:1558-1564.

33. Scalliet, G., Bowler, J., Luksch, T., Kirchhofer-Allan, L., Steinhauer, D., Ward, K., Niklaus, M., Verra, A., Csukai, M., Daina, A., and FonnéPfister, R. 2012. Mutagenesis and functional studies with succinate dehydrogenase inhibitors in the wheat pathogen Mycosphaerella graminicola. PLoS One 7:e35429.

34. Sierotzki, H., Parisi, S., Steinfield, U., Tenzer, I., Poirey, S., and Gisi, U. 2000. Mode of resistance to respiration inhibitors at the cytochrome bc1 complex of Mycosphaerella fijiensis field isolates. Pest Manage. Sci. 56:833-841.

35. Sierotzki, H., and Scalliet, G. 2013. A review of current knowledge of resistance aspects for the next generation succinate dehydrogenase inhibitor fungicides. Phytopathology 103:880-887.

36. Skinner, W., Bailey, A., Renwick, A., Keon, J., Gurr, S., and Hargreaves, J. 1998. A single amino-acid substitution in the iron-sulphur protein subunit of succinate dehydrogenase resistance to carboxin in Mycosphaerella graminicola. Curr. Genet. 34:393-398.

37. Stammler, G., Brix, H. D., Glattli, A., Semar, M., and Schoefl, U. 2007. Biological properties of the carboxamide boscalid including recent studies on its mode of action. Pages 40-45 in: Proc. XVI Int. Plant Prot. Cong. Glasgow, Scotland, UK.

38. Stewart, C., and Via, L. E. 1999. A rapid CTAB DNA isolation technique useful for RAPD fingerprinting and other PCR applications. BioTechniques 14:748-749.

39. Veloukas, T., Leroch, M., Hahn, M., and Karaoglanidi, G. S. 2011. Detection and molecular characterization of boscalid-resistant Botrytis cinerea isolates from strawberry. Plant Dis. 95:1302-1307.

40. Veloukas, T., Markoglou, A. N., and Karaoglanidi, G. S. 2013. Differential effect of SdhB gene mutations on the sensitivity to SDHI fungicides in Botrytis cinerea. Plant Dis. 97:118-122.

41. Wharton, P., Fairchild, K., Belcher, A., and Wood, E. 2012. First report of in-vitro boscalid-resistant isolates of Alternaria solani causing early blight of potato in Idaho. Plant Dis. 96:454.

42. Yin, Y. N., Kim, Y. K., and Xiao, C. L. 2011. Molecular characterization of boscalid resistance in field isolates of Botrytis cinerea from apple. Phytopathology 101:986-995. 